\title{
Galactose-alpha-1,3-galactose: Possible Role in Red Meat Allergy
}

\section{Makenzie L Fulmer ${ }^{1}$, Guha Krishnaswamy ${ }^{2,3}$ and Andromeda M Nauli1,2*}

${ }^{1}$ Department of Health Sciences, College of Public Health, USA

${ }^{2}$ Division of Allergy and Immunology, Department of Internal Medicine, Quillen College of Medicine, East Tennessee State University, Johnson City, TN, USA

${ }^{3}$ James H. Quillen VA Medical Center, Mountain Home, TN, USA

\section{Alpha-gal in Red Meat}

Recent studies have indicated that patients who exhibit immediate hypersensitivity to red meat also demonstrate IgE-mediated immunoreactivity to oligosaccharide galactose-alpha-1,3-galactose (alpha-gal) [1]. Why and how this happens is unclear, though several groups seem interested in this phenomenon. It is possible that an evolutionary or developmental basis exists for this observation.

The alpha-gal epitope is distinctive in its dispersal in mammals; it is generously expressed in non-primate mammalian, New World monkeys, and prosimians, where by contrast an IgG antibody binding to this epitope is produced naturally in humans, Old World monkeys, and apes [2]. Non-primate mammals, such as bovine and porcine species, contain a larger proportion of red meat (slow and intermediate fibers) than ground-based birds. Ground-based birds, chickens and turkeys, in contrast, contain a significant amount of white meat, especially in their chest muscles (fast fibers). Slow and intermediate muscle fibers exhibit a higher resistance to fatigue, require more oxygen supply, and therefore contain a more extensive vascular supply. Due to increased amounts of blood capillaries surrounding slow and intermediate muscle fibers, there is an increase of basement membrane (BM). Laminin, a glycoprotein present abundantly in the basal lamina layer of $\mathrm{BM}$, has been shown to contain $\mathrm{N}$-linked oligosaccharides in large amounts exhibiting the alpha-gal structure [3]. It is thereby assumed that red meat, primarily in non-primate mammals, will demonstrate a higher quantity of alpha-gal.

The antibody against alpha-gal that is found naturally in nonimmunocompromised humans, Old World monkeys, and apes is in the form of IgG and represents $1 \%$ of the immunoglobulins dispersed in these subjects [4]. IgG is the most abundant class of immunoglobulins found in the plasma and primarily functions to inhibit the infectivity and toxicity of viruses and toxins, respectively. IgG also works by activating complement and thereby facilitating the removal of pathogens by phagocytic ingestion. However, as discussed below, allergic and serious anaphylactic reactions often involve immunoglobulin E (IgE).

\section{IgE-mediated Hypersensitivity Reaction}

Case studies executed by Commins et al. [5], have identified patients with IgE antibodies to alpha-gal. These patients had previously experienced symptoms of anaphylaxis and associated allergic reactions following the consumption of red meat [5]. Immunoglobulins characterized by $\varepsilon$ heavy chains (IgE) function in sensitizing mast cells which can lead to an allergic response. It is believed that the immune response responsible for the switch of immunoglobulin class from IgG to IgE is mediated by two categories of signals. These signals favor differentiation of naive $\mathrm{T}$ cells to a $\mathrm{T}_{\mathrm{H}} 2$ phenotype and activation of IgE production by B cells. In individuals that are predisposed, possibly due to environmental or dietary factors, mast cells and basophils systematically release histamine and other mediators, leading to signs and symptoms of anaphylaxis [6].

\section{Unusual Characteristics of Allergic Reactions to Red Meat}

Conventional teachings of related food allergies conclude that the IgE-mediated responses are due to a protein-based allergen present in the food. Allergic reactions are typically manifested within 5-30 minutes following allergen ingestion. Red meat allergy, however, is characterized by an IgE-mediated response to what is presumed to be a carbohydrate epitope (alpha-gal) with hypersensitivity occurring up to 5 hours after a meal containing the presumed allergen [5]. Due to the unique characteristics of red meat allergy, initial diagnosis is difficult and depends on a detailed patient history [7]. Other variables that could have an effect on the amount of alpha-gal epitope being presented to a patient are portion size and preparation of the meat. The different methods for cooking (grilled, baked, fried) as well as duration of cooking (rare to well-done) may alter the amount of alpha-gal. While clinical symptoms are more likely to manifest from elevated levels of specific IgE, an increased level of IgE to alpha-gal in circulation serves to predict neither the severity nor occurrence of an allergic reaction [7].

\section{Arthropods and Alpha-gal}

Development of allergy to red meat has the potential of being caused by many genetic factors that could predispose an individual [1]. However, there is evidence that tick bites may contribute a major role in the development [8]. The presumed role of tick bites, specifically from Amblyomma americanum, is supported by epidemiological evidence showing IgE antibodies to alpha-gal to be specific to regions where tick bites are more common. There is also a correlation between the presence of IgE antibodies specific for tick proteins and IgE antibodies specific for alpha-gal [8]. Studies have also shown that patients who suffer from Chagas' disease and Leishmania infection have a significant increase in serum titer of antibody to alpha-gal [9]. Both pathologies result from parasites that are introduced to individuals after suffering from a bite from the associated vector. Triatomine bugs are the vectors responsible for the transmission of Trypanosoma cruzi causing Chagas' disease, and sandflies are responsible for the transmission of Leishmania spp. causing Leishmaniasis. The sum of this data supports arthropods being a cause of the alpha-gal IgE formation in humans, which may be associated with red meat allergy.

${ }^{*}$ Corresponding author: Andromeda M Nauli, East Tennessee State University, Box 70673, Johnson City, TN 37614-1709, USA, Tel: (423) 4396186; Fax: (423) 439-4562; E-mail: naulia@etsu.edu

Received July 06, 2013; Accepted July 10, 2013; Published July 12, 2013

Citation: Fulmer ML, Krishnaswamy G, Nauli AM (2013) Galactose-alpha-1,3galactose: Possible Role in Red Meat Allergy. J Biosafety Health Educ 1: e110. doi:10.4172/2332-0893.1000e110

Copyright: (c) 2013 Fulmer ML, et al. This is an open-access article distributed under the terms of the Creative Commons Attribution License, which permits unrestricted use, distribution, and reproduction in any medium, provided the original author and source are credited. 
Citation: Fulmer ML, Krishnaswamy G, Nauli AM (2013) Galactose-alpha-1,3-galactose: Possible Role in Red Meat Allergy. J Biosafety Health Educ 1: e110. doi:10.4172/2332-0893.1000e110

Page 2 of 2

\section{Future Directions}

While not confirmed, accumulating evidence supports the notion that red meat allergy is caused by an IgE-mediated response to alphagal. Clinical studies and epidemiological data have found a possible correlation between increased levels of IgE specific to alpha-gal and a history of direct interaction with certain species of arthropods. While this correlation is valuable and informative, the studies and results are not conclusive. Further studies on the mechanism of severe allergy to red meat are warranted.

\section{Acknowledgements}

This work is supported by RDC Major Grant and Interdisciplinary Grant; Department of Health Sciences, College of Public Health, East Tennessee State University.

\section{References}

1. Saleh H, Embry S, Nauli A, Atyia S, Krishnaswamy G (2012) Anaphylactic reactions to oligosaccharides in red meat: a syndrome in evolution. Clin Mol Allergy 10: 5

2. Macher BA, Galili U (2008) The Galalpha1, 3Galbeta1, 4GIcNAc-R (alpha-Gal) epitope: a carbohydrate of unique evolution and clinical relevance. Biochim Biophys Acta 1780: 75-88.

3. Christiansen D, Mouhtouris E, Milland J, Zingoni A, Santoni A, et al. (2006) Recognition of a carbohydrate xenoepitope by human NKRP1A (CD161) Xenotransplantation 13: 440-446.

4. Galili U, Rachmilewitz EA, Peleg A, Flechner I (1984) A unique natural human IgG antibody with anti-alpha-galactosyl specificity. J Exp Med 160: 1519-1531.

5. Commins SP, Satinover SM, Hosen J, Mozena J, Borish L, et al. (2009) Delayed anaphylaxis, angioedema, or urticaria after consumption of red meat in patients with IgE antibodies specific for galactose-alpha-1,3-galactose. J Allergy Clin Immunol 123: 426-433.

6. Commins SP, Platts-Mills TA (2009) Anaphylaxis syndromes related to a new mammalian cross-reactive carbohydrate determinant. J Allergy Clin Immunol 124: $652-657$.

7. Siles RI, Hsieh FH (2011) Allergy blood testing: A practical guide for clinicians Cleve Clin J Med 78: 585-592.

8. Commins SP, James HR, Kelly LA, Pochan SL, Workman LJ, et al. (2011) The relevance of tick bites to the production of $\mathrm{IgE}$ antibodies to the mammalian oligosaccharide galactose- $\alpha-1,3$-galactose. J Allergy Clin Immunol 127: 12861293.

9. Avila JL, Rojas M, Galili U (1989) Immunogenic Gal alpha 1----3Ga carbohydrate epitopes are present on pathogenic American Trypanosoma and Leishmania. J Immunol 142: 2828-2834. 